\title{
Technological Perspectives for Propulsion on Nuclear Attack Submarines
}

\section{Luciano Ondir Freire, Delvonei Alves de Andrade}

Nuclear and Energy Research Institute, Instituto de Pesquisas Energéticas e Nucleares, São Paulo, Brazil

Email: luciano.ondir@gmail.com

How to cite this paper: Freire, L.O. and de Andrade, D.A. (2016) Technological Perspectives for Propulsion on Nuclear Attack Submarines World Journal of Nuclear Science and Technology, 6, 309-319. http://dx.doi.org/10.4236/winst.2016.64028

Received: October 6, 2016

Accepted: October 23, 2016

Published: October 26, 2016

Copyright $\odot 2016$ by authors and Scientific Research Publishing Inc. This work is licensed under the Creative Commons Attribution International License (CC BY 4.0).

http://creativecommons.org/licenses/by/4.0/

\begin{abstract}
This work aimed at proposing a new combination of technologies to improve military performances and reduce costs of nuclear attack submarines, without overlooking safety constraints. The last generation of nuclear attack submarines increased size to meet safety and operational requirements, imposing huge burden on costs side, reducing fleet size. The limitations of current Technologies employed were qualitatively discussed, explaining their limitations. There are new technologies (plate and shell heat exchangers) and architectural choices, like passive safety, and segregation of safety and normal systems, which may lead to reduction of costs and size of submarines. A qualitative analysis was provided on this combination of technologies, stressing their commercial nature and maturity, which reduced risks. The qualitative analysis showed the strong and weak points of this proposal, which adopted the concept of strength in numbers. Concluding, new Technologies enabled the existence of $3800 \mathrm{t}$ nuclear attack submarines with powerful propulsion systems and good acoustic discretion.
\end{abstract}

\section{Keywords}

Plate and Shell Heat Exchangers, Nuclear Attack Submarines, PWR

\section{Introduction}

State of art nuclear attack submarines (Virginia, Astute and Suffren classes) have nuclear reactors that depend on electric energy and active engineered safety features to keep a safe state in case of design basis accidents. It is important to note that even after shutdown, the reactor core keeps generating residual heat, which may melt the core internals if emergency core cooling system does not work. Therefore, design needs to add redundancies on emergency long term electrical generation (diesel generators) to render acceptable the risk of total loss of electric power following a design basis accident on 
reactor. Such redundancies, along increase in payload, imposed greater displacements on the last generation of nuclear attack submarines if compared with previous generation. The surface displacements reached the range 7000 - 8000 tons for submarines using loop reactors and about 5000 tons for the submarine using an integral architecture reactor [1].

Evidently, this displacement growth had drawbacks in propulsion performance, due to growth of wetted surface, causing augmentation of drag, besides costs growth. Each nuclear class component, produced under nuclear quality standards, has an acquisition cost about one order of magnitude greater than its normal equivalent [2], and requires constant inspections during service life.

In the field of land commercial nuclear power plants, vendors started to propose simpler solutions with less components and passive safety, which is able to cool the core after a design basis accident without electrical energy supply or active components. Such designs were commercially successful and many units of AP1000 are under construction, some soon entering in operation [3]. An example of passive safety is the nuclear containment of International Reactor Innovative and Secure, IRIS, which assures core cooling by gravity in case of loss of coolant accidents and reduces containment footprint [4]. In IRIS, all components are integrated in a single pressure vessel, eliminating pipes and reducing frequency of loss of coolant accidents, simplifying the nuclear plant and reducing its volume, what is interesting for naval applications. In case of accidents, the residual heat is removed by containment walls to external fluid, eliminating the need of pumps or any active device in the long term, which reduces the need of electric energy.

In the end of eighties' decade, advances in fabrication technology, like laser welding, allowed the fabrication of shell and plate heat exchangers, which have similar capabilities as shell and tube heat exchangers, but are more compact and reliable [5]. Shell and plate heat exchangers work with pressures temperatures almost as elevated as shell and tube heat exchangers, reaching pressures of 150 bar and temperatures of $600^{\circ} \mathrm{C}$ [5]. Shell and plate heat exchangers have suitable ranges of temperature and pressure for application on pressurized water reactors and have much smaller volume, as seen in Figure 1 [5].

The nuclear reactor core generates high energy ionizing radiation which requires a radiological shield of about 1 meter thick [6]. The reactor shielding, also called primary shielding, blocks gamma rays and high energy neutrons from fission reactions inside

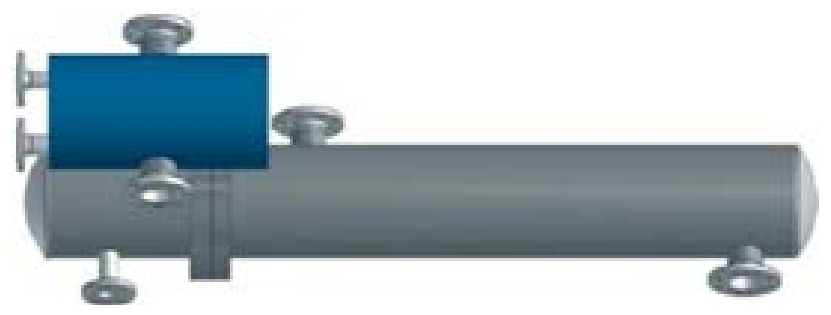

Figure 1. Comparison between shell and plate heat exchanger (top) and shell and tube heat exchanger (below) with same thermal load. 
the active nuclear reactor core. In loop reactors, the gamma decay of the short lived ${ }^{16} \mathrm{~N}$ to ${ }^{16} \mathrm{O}$ in pipes and steam generator imposes the adoption of another shielding to protect the crew [6], which implies in great addition of weight to the ship. The adoption of integrated designs greatly reduces the weight and volume inside a ship because there is no need of a secondary shielding to protect the crew from ionizing radiation from short lived isotopes generated in the coolant within the core.

In integral designs, the same shielding blocks the fission radiation and the gamma radiation from ${ }^{16} \mathrm{~N}$ isotopes. In other words, integral designs eliminate the need of secondary shielding, roughly reducing plant weight by half. The total plant volume is also reduced due to elimination of space for primary pipes, steam generators, seating and space for visual inspection during service life.

French integral nuclear reactors use one shell and tube heat exchanger on top of reactor vessel to generate steam. This solution has limitations to maximum power once tube sheets cannot have diameters beyond a certain value due to technological constraints. Once submarine diameter limits also the height of the steam generator, this volume limitation reduces the maximum power that can be extracted from the nuclear reactor, reducing the maximum speed of the submarine.

On the other hand, the shell and plate heat exchangers allow construction of integrated reactors with any shape, allowing greater powers, achieving performances like those of loop reactors in a reduced footprint. There is already a patent that shows an illustration of such concept [7].

\section{Assumptions}

It is assumed the budget for defense is constant and independent of technology adopted. This assumption is justified by the fact most countries use a fraction of gross domestic product to define military expenditures. Therefore, it is possible either to have many cheap submarines or a few expensive ones. Another assumption is that vertical launchers are not required, which is justified by the fact most nuclear attack submarines does not have vertical launchers. It is assumed that a nuclear attack submarine must be able to realize blockade operations against enemy merchant ships and be able to outrun the fastest ships, which run at around 25 knots nowadays. This assumption is justified by previous use of submarines in Second World War. It is assumed that only proven technologies should be employed. On the other side, the technologies must be far from becoming obsolete once a submarine program has a long life and requires spare parts during its life. This assumption is justified because a delays or downtimes in such expensive systems as nuclear attack submarines represent enormous financial damages. Last, but not least, the machinery of a submarine needs to be silent at low speed but not at high speed. This assumption is justified by the fact that at high speed, hydrodynamic noise is preponderant.

\section{Method and Development}

Only a qualitative analysis of weights and volumes and power of propulsion systems is 
performed, comparing past solutions and examples. Only orders of magnitude are taken into account, without precise calculations. For example, the six tenths law is used to estimate costs in function of performances. Another example is the noise level in function of the shaft speed of a rotating machine. This work shows an option without providing calculations which are not interesting for pre conceptual studies.

The intrinsic characteristics of each nuclear reactor architecture (integral and loops) are discussed in terms of integration constraints of weight and volume. Second step is to demonstrate the possibility of using plate and shell heat exchangers to further reduce nuclear reactor. The analysis goes on by reviewing the types of propulsion systems and how to reduce their volume keeping performance, reliability and acoustic discretion.

A propulsion system should be light and compact. The best proven architecture to achieve this is the integral architecture because it does not need space for primary pipes and secondary shielding. In order to achieve high power, the steam generation must be done by plate and shell heat exchangers. A possible physical arrangement could be a set of plate and shell heat exchangers in vertical position organized in the form of annulus, as shown in Figure 2 and Figure 3. The base heat exchanger is the XPS50 of GESMEX. The material chosen is steel AISI $316 \mathrm{~L}$ with $1.25 \mathrm{~mm}$ thickness. Such vertical position for this kind of heat exchanger was already employed successfully in industry. Both feed water piping and steam piping are in the top, easily accessed when the reactor vessel is opened. If a heat exchanger suffers some leakages, it is easy replace it, removing it by the top. In case of inclination of the ship, it is possible to have liquid water exiting some

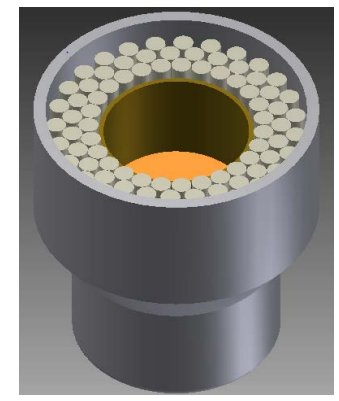

Figure 2. Arrangement in form of annulus.

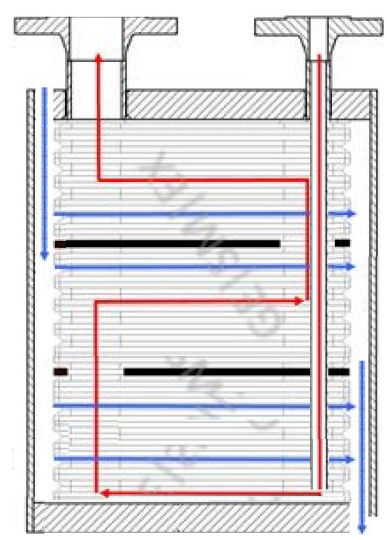

Figure 3. Plate and shell heat exchanger in vertical position. 
heat exchanger due to gravity effects. The heat exchanger in the lowest position would have bigger flow because of hydrostatic pressure, creating the risk of partial evaporation, which in turn reduces charge losses, increasing still more the liquid water content at outlet. In order to prevent a huge liquid water fraction entering the turbine and causing erosion, the following measures are necessary:

- To add flow restrictions at inlet of secondary side of each heat exchanger in order to reduce flow unbalance;

- To have super heating margin on the outlet steam (or margin on the heat transfer area), so even if there is unbalance, it is not sufficient to overcome margins;

- To stop operation to when inclination angle surpasses design limits, once it is not possible to design a reactor which is able to operate at any inclination. Besides, if the reactor is shutdown, the turbine receives no steam and is in a safe condition.

It was found that at angles of 45 degrees from vertical, three passes heat exchangers with $21 \%$ margin in heat transfer area should not have problems with liquid water at outlet.

Typically in PWR, steam generators have a double role: they generate steam to be used in power conversion system and, in accidental scenario, they contribute to perform the emergency secondary heat removal function [8]. This solution imposes constraints in design and operation, like redundancy on steam generators, periodic inspections, classification of part of steam generators in class 1 and part in class 2, segregation and independence.

If the safety function of emergency secondary heat removal is performed by other heat exchangers not used in normal operation, the heat exchanger used for power conversion does not need to be redundant and classified. Of course, failure of non-nuclear safety equipment must not impair safety functions. In current designs, the steam generators tubes are part of reactor coolant pressure barrier and therefore need to be classified as safety class 1 [8]. It is important to note that operation has wear effects over the tubes, which frequently have leakages and need to be plugged.

On the other hand, if plate and shell heat exchangers are used instead of shell and tube, it is possible to place the plate packs inside the pressure vessel. In this case, leakages or ruptures in the plate pack do not constitute a breach in the reactor coolant pressure barrier, as shown in Figure 4.

Of course, steam lines and feed water lines need to be class 1 up to isolation valves

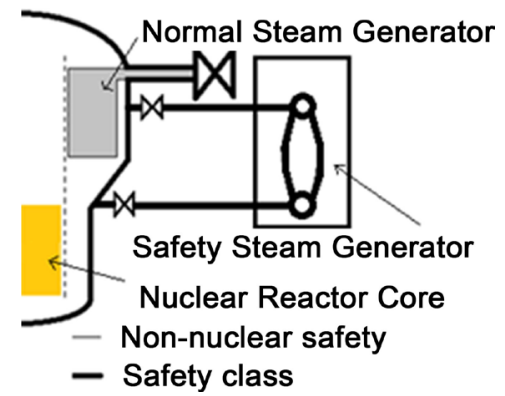

Figure 4. Normal steam generator within reactor vessel and external safety steam generator. 
because the plate packs, being non-nuclear safety, do not receive credit in design basis scenarios. Once plate packs are located inside pressure barrier, a leakage can only cause a limited loss of coolant, which will stop as soon as isolation valves are closed, affecting only plant availability, but not plant safety.

Safety steam generators may be shell and tube type heat exchangers located in an ambient pressure tank, with natural circulation drive for primary coolant, in similar fashion as IRIS [4]. Those heat exchangers must only be pressurized for tests and accidental scenarios.

Once the plate packs work always under compression because the external pressure (primary coolant, around 150 bar) is higher than internal pressure (secondary fluid, around 64 bar), catastrophic ruptures are unlikely to occur. Of course, small leakages may still happen with frequency higher than design basis accidents defined in nuclear standard [8]. In practice, it may be found that the association of one big internal steam generator for normal operation and two or three small steam generators dedicated to design basis accidents may have better availability and safety than current designs. The reason for better safety is that safety heat exchangers do not suffer wear in normal operation and the reason for better availability is smaller frequency of leakages in pipes and plate packs working under compression.

In the power conversion system, there are three main types of propulsion architectures: turbo mechanical (the most common), turbo electric (the most silent) and hybrid (the newest). The turbo mechanic propulsion is the most compact and allows reaching higher speeds because it has less energy conversion stages. It is more powerful but it also is noisy. Figure 5 shows a simplified example.

Turbo electric propulsion systems (Figure 6) use fixed speed power generators, operating at optimum speed, having superior efficiency when operating at lower speeds if compared with turbo mechanical systems. The operation at fixed speed allows machines to be designed to be more silent at this shaft speed, which results in good acoustic discretion properties. On the other hand, electric power generators, rectifiers, drivers, electric motors and associated seating are heavy and occupy a lot of space. Once submarines are limited in terms of internal volume, historically, submarines with this architecture have maximum speeds between $25 \%$ and $40 \%$ smaller than submarines

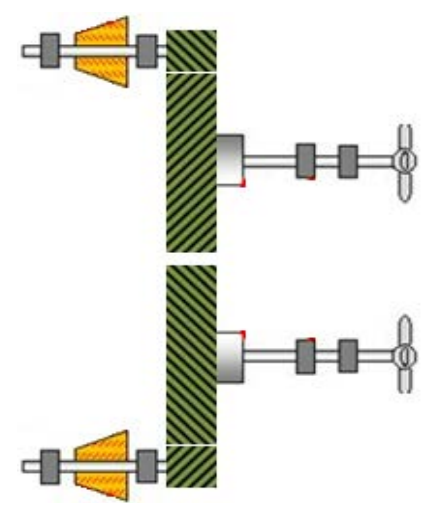

Figure 5. Turbo mechanical propulsion. 


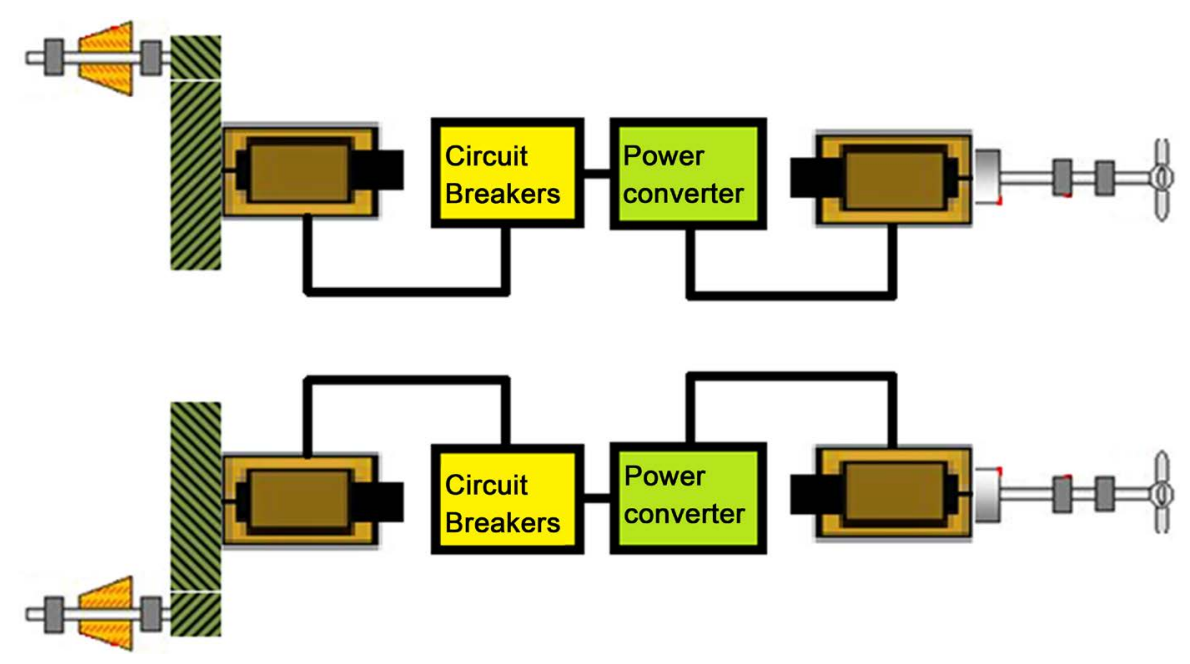

Figure 6. Turbo electrical propulsion.

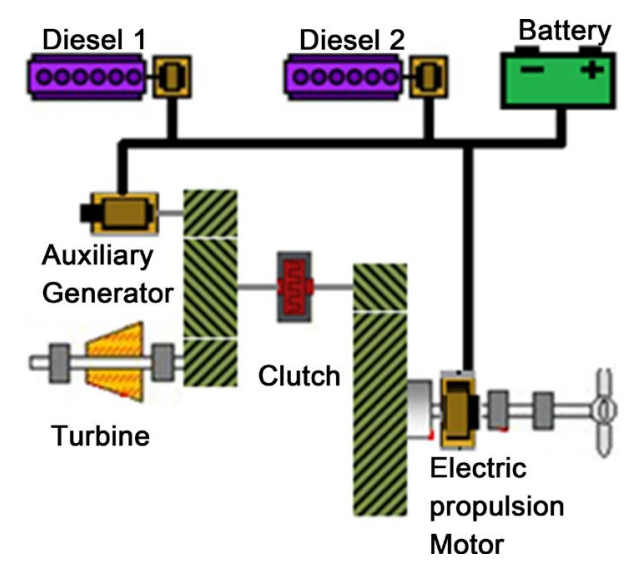

Figure 7. Hybrid parallel propulsion.

with turbo mechanical architectures. Examples of submarines with turbo electric architecture are SSN Tulibee and Ruby class submarines.

Finally, the hybrid propulsion systems have the advantages of both previously described architectures. It is compact and allows turbines operation at constant speed, which gives good acoustic discretion properties. Figure 7 presents a variant that is the hybrid parallel architecture. At low power and speed, the clutch allows the power generators operate at high speed, recharging the battery and providing auxiliary power to the ship, while a tiny propulsion motor provides propulsion. To reach high speeds, the clutch connects the turbine to the propulsion shaft line gearbox. The propulsion motor can still enhance the power at the shaft line for a limited time by drawing energy from the battery.

Of course, when the clutch connects the turbine to the shaft line and becomes the prime mover, the propulsion system is as noisy as a turbo mechanical one. But, at high speeds, the hydro dynamic noise is higher than machinery noise, which means that there is no gain in being silent at high speeds when the turbulent flow around the hull produces a lot of noise. It is important to note that a submarine stays most of the time 
at low speed, being the use of high speed a small fraction of time. In the hybrid parallel architecture shown, both the tiny electric propulsion motor and the generator may work as motor or generator. This gives flexibility, providing redundant downgraded modes of operation, keeping a minimum propulsion capability after the failure of any component.

In the power conversion system part, typically submarines have adopted two segregated sides of turbines to achieve reliability goals. Such solution has drawbacks of being expensive and large in terms of weight and volume if compared with a single turbine. On grounds of the six tenths law [9], it may be stated that two turbines are $32 \%$ more expensive than a single turbine with same power. Besides, two turbines require almost twice more space than a single turbine with same power because all auxiliary systems need to be duplicated. It is important to note that in peace time, after losing one side of propulsion system due to equipment failure, the submarine needs to come back to repairs. Once the two sides of propulsion system are always in operation, the failure rate is doubled, reducing the mission reliability.

A modern solution is the hybrid parallel architecture (Figure 7), employed in merchant ships and tugs. Such solution allows keeping a minimal propulsion capability in case of a single failure, being as reliable as the redundant solution to return to home, but cheaper and more powerful. The mission reliability is superior because the quantity of components in operation is reduced.

\section{Results and Discussion}

Adopting a propulsion system with hybrid parallel architecture, an integral reactor with shell and plate steam generators, it is estimated that is possible to reach a thermal power of $64 \mathrm{MW}$ within a hull of $8.8 \mathrm{~m}$ of diameter. Once the nuclear safety is assured by passive elements, diesel and batteries do not need to be nuclear safety classified, having smaller redundancies and cost as they will only be required to power the submarine during return home.

This submarine could have a surface displacement similar to the Permit class ( 3800 $\mathrm{t}$ ), shaft line power of $11 \mathrm{MW}$ and maximum speed of 28 knots. The hybrid propulsion allows having acoustic discretion similar to SSN Tulibee at low speeds and maximum speed similar to Permit class. The limitation is that both properties are not simultaneous. If the clutch is disconnected, the propulsion system is silent but slow. If it is connected, high speeds may be reached at expense of acoustic discretion.

This submarine acoustic discretion is a central issue. The noisiest components in a nuclear attack submarine, in reducing order, are: turbines, primary pumps and shaft line reducing gears. All those machines are rotating machinery, which have many resonance frequencies. Whenever their shaft speed matches resonance frequencies, high amplitude oscillations are produced, generating noise.

In order to improve acoustic discretion, rotating machinery must have their masses reduced, its rotation speed must be elevated, a single rotation speed must be adopted and their carcass must be decoupled of the hull by flexible seating or cradles. In order 
to reduce mass, one solution is to employ components dedicated to operation at low speeds of the submarine, when flows are small. In this case, part of primary coolant pumps, of seawater condenser pumps, of condensate extraction pumps and feed water pumps must be sized to low speeds, when the clutch is disconnected.

In a submarine, turbines should work at their nominal rotation due to three reasons: first, to increase energy conversion efficiency; second, to reduce noise; and third, to reduce propagation of its noise in sea water, which is reduced at higher frequencies. Figure 8 shows a $130 \mathrm{~Hz}$ nominal rotation shaft vibration in function of its frequency. It is easy to see that a turbo mechanical propulsion turbine at low speeds may be near a resonance frequency, and even if it not the case, the turbine noise would be around 3 orders of magnitude greater than at nominal speed. On the other hand, a hybrid parallel architecture uses its turbine at nominal speed when the submarine is at low speeds, fact that reduces vibration, which in turn allows stating that hybrid parallel propulsion has potential to be silent.

About the primary pumps, the use of integral design may allow to use the reactor vessel as a cradle, decoupling it from the hull by the use of flexible seating. Another advantage is that integral designs facilitate natural circulation, allowing the operation at low power without active pumping. However, natural circulation alone is very unstable and unsuitable to submarine operation. A better solution is to have a very small pump with capacity only to stabilize natural circulation. This small pump could have other functions, like driving coolant into purification system. This pump may be very silent if it is fixed on the reactor vessel, which may be decoupled from hull.

Finally, about the shaft line reduction gear, in hybrid parallel architecture, it does not work at low speeds. At low speeds, the prime mover is a tiny silent electric propulsion motor whose frequency of rotation is below detection range of modern passive sonars.

About the use of plate and shell heat exchangers, its fabrication feasibility is assured by the fact plate and shell heat exchangers are a commercial of the shelf solution,

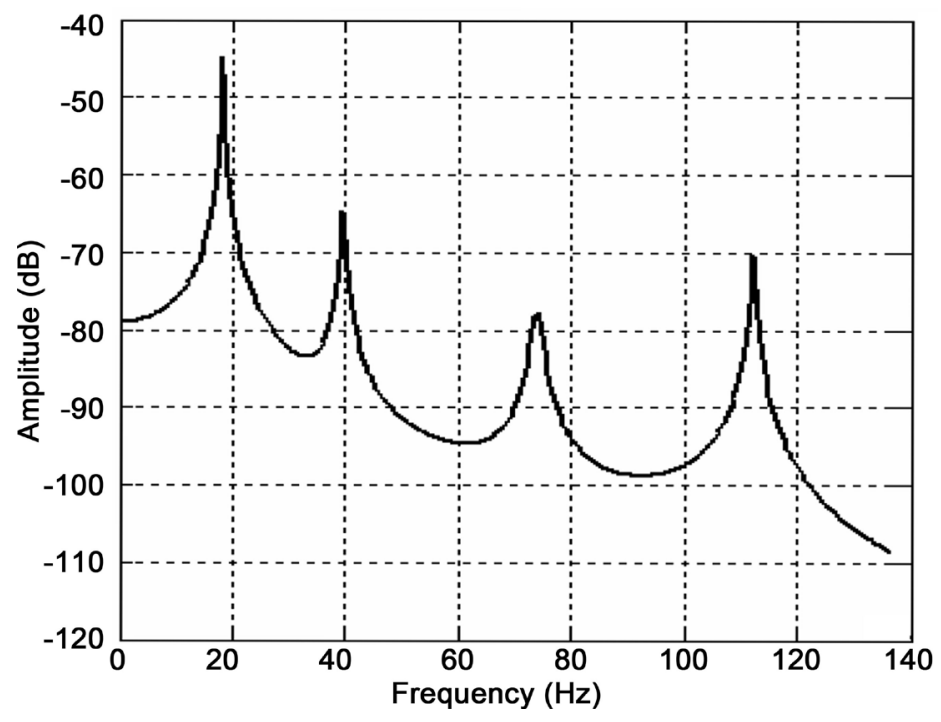

Figure 8. Example of rotor vibration in function of frequency. 
already proven in industry. The water chemistry requirements are not set by the heat exchanger, but by turbine. Once the steam is completely vaporized and superheated, any solid impurities in feed water are dragged along the steam and may cause corrosion on the turbine. According to EPRI [10], once through steam generators must work with the lowest possible levels of solid impurities to be adequate with secondary system design. This means that the water chemistry is not a problem to this type of heat exchanger and the integration with a secondary system is feasible. The access for inspection is easy because all pipes are in superior part and each heat exchanger may be easily replaced.

The modular architecture allows easy identification of the heat exchanger with leakages when the pressure vessel is open, once it is enough to pressurize the secondary side with air and see where the bubbles appear. The same way of IRIS, the elimination of pipes reduces the number of possible failures, reduces plant footprint and the size of nuclear containment. This means greater payload for a submarine. Additionally, the integral reactor design eases radiological shielding design and reduces crew exposition.

The functional segregation of the normal and safety functions has the advantages of use of industry standards for the major part of heat exchangers (large area for power conversion) and makes the emergency secondary heat removal more reliable. Once emergency secondary heat removal heat exchangers are not used continuously, they do not suffer wear.

Although non-nuclear safety class, the power conversion heat exchangers are part of the first level of defense in depth and must avoid frequent incidents. The frequency of problems in plate and shell heat exchangers is estimated to be lower than current designs where tubes work in traction. Because the plate pack is under compression, there should not be propagation of small defects or creep. Of course, small leakages may occur, but they should not cause major plant downtimes.

\section{Conclusions}

Adoption of industry proven technologies can allow power densities improvements in nuclear attack submarines propulsion. Besides, the adoption of passive safety can reduce size and cost of nuclear reactors, allowing use of diesel generators without nuclear safety classification. Instead of two batteries, a single battery and much less pumps and pipes could be employed, and the submarine still would be safer than current designs. The use of integral designs can contribute to acoustic discretion, weight reduction, volume reduction and radiation doses on crew members.

With such solutions, it is possible to build nuclear attack submarines with half of surface displacement of state of art submarines Virginia class and Astute class, with a cost less than half of those submarines. The reduced cost allows formation of numerous fleets, whose cost can be even further reduced due to learning effects. The speed should allow outrunning the fastest merchant ships, making this submarine a formidable blockade weapon. And acoustic discretion could be yet superior to state of art submarines. 
This new submarine can the built using only mature and proven technologies, tested for about 20 years, which means new developments at level of components are not required. It is just about a new form of integration of existing technologies.

\section{References}

[1] Saunders, S.C. (2015) Jane's Fighting Ships 2014-2015: Yearbook. 117th Edition, IHS Inc., London.

[2] US Nuclear Regulatory Commission (2003) Risk-Informed Categorization and Treatment of Structures, Systems and Components for Nuclear Power Reactors, 10 CFR 50.69, Regulatory Analysis.

[3] Reuters (2014) China Seen Buying Westinghouse Reactors for \$24 Billion Nuclear Energy Projects. http://www.reuters.com/article/2014/04/21/china-nuclear-idUSL3N0ND1GS

[4] Carelli, M.D., et al (2004) The Design and Safety Features of the IRIS Reactor. Nuclear Engineering and Design, 230, 151-167. http://dx.doi.org/10.1016/j.nucengdes.2003.11.022

[5] Klahm, T. (2009) When Two Worlds Merge-A Compact and Efficient Plate Heat Exchanger Combined with a Pressure and Temperature Resistant Shell. http://www.gesmex.com/fachbericht-e303.html

[6] Theodore Rockwell III (1950) Reactor Shielding Manual. Naval Reactors Branch, Division Of Reactor Development, United States Atomic Energy Commission, First Edition, USA.

[7] Charles Fribourg (2012) Nuclear Reactor Having Plate or Micro-Channel Heat Exchangers integrated in the Vessel. WIPO Patent WO 2013/153076 A1.

[8] American Nuclear Society (1988) Nuclear Safety Criteria for the Design of Stationary Pressurized Water Reactor Plants: ANSI/ANS-51.1-1983(R1988): Technical Standard. USA. 92 p.

[9] Williams Jr., R. (1947) Six-Tenths Factor Aids in Approximating Costs. Chemical Engineering, 54, 124-125.

[10] EPRI (2000) PWR Secondary Water Chemistry Guidelines-Revision 5. EPRI, Palo Alto, CA, TR-102134-R5.

Submit or recommend next manuscript to SCIRP and we will provide best service for you:

Accepting pre-submission inquiries through Email, Facebook, LinkedIn, Twitter, etc. A wide selection of journals (inclusive of 9 subjects, more than 200 journals)

Providing 24-hour high-quality service

User-friendly online submission system

Fair and swift peer-review system

Efficient typesetting and proofreading procedure

Display of the result of downloads and visits, as well as the number of cited articles

Maximum dissemination of your research work

Submit your manuscript at: http://papersubmission.scirp.org/

Or contactwjnst@scirp.org 